\title{
Impact of tumor size on depth of invasion and number of Lymph nodes infiltration in esophageal cancer
}

\author{
Ahmed S Elgammal, MD ${ }^{1^{\star}}$, Ihab S Ahmed MD², Walla Abdelgawad,MD ${ }^{3}$, Essam Elshiekh, MD ${ }^{4}$ \\ ${ }^{1}$ General surgery department, Menofia faculty of medicine, Menofia University, Egypt. ${ }^{2}$ Surgical on- \\ cology department, $\mathrm{NCl}$, Cairo university, Egypt. ${ }^{3}$ Pathology department, Suez faculty of medicine, \\ Suez university, Egypt. ${ }^{4}$ Surgical oncology department, Tanta Cancer Center, Egypt.
}

\section{ABSTRACT}

Introduction: Esophageal cancer (EC) is one of the deadliest malignancies worldwide and is often diagnosed in advanced stages. It is the 8th most common cancer in the world and is the 6th most common cause of cancer related deaths, having a 5 -year survival rate of less than $20 \%$ despite advances in treatment. It has a poor prognosis due to the late diagnosis and the lack of early presenting symptoms. In the United States, stage IV is the most common stage at the time of diagnosis.

Methods: Eighty-seven fit patients were recruited for this multi-institutional clinical prospective study in the period from the start of January 2014 to the end of December 2020, diagnosed as cancer esophagus in by endoscopic biopsy and underwent surgical treatment according to stage at the centers participating in this study.

Results: In pre-operative biopsy, Adenocarcinoma was diagnosed in 39/87 cases (44.8\%) distributed as (5 in GEJ and 34 diagnosed in lower esophagus) while squamous cell carcinoma (SCC) diagnosed in 48/87 cases (55.2\%) distributed as (28 in lower part, 10 in middle part and 9 in upper esophagus respectively) and only one case out of 87 cases diagnosed as undifferentiated carcinoma of lower esophagus. We found significant association between the increased tumor size and the increase depth of invasion and thenumber of harvested lymph nodes.

Conclusion: As the tumor size increased (cutoff point $3 \mathrm{~cm}$ ), the depth of invasion through the layers of esophagus and the number of the infiltrated lymph nodes will increase, and this is associated with poor prognosis and increase in mortality rate from the esophageal cancer.

Keywords: esophageal carcinoma, Lymph nodes, depth of invasion, tumor size
${ }^{*}$ Correspondence to Author:

Ahmed S Elgammal

General surgery department, Menofia faculty of medicine, Menofia University, Egypt.

How to cite this article:

Ahmed S Elgammal, Ihab S Ahmed, Walla Abdelgawad, Essam Elshiekh. Impact of tumor size on depth of invasion and number of Lymph nodes infiltration in esophageal cancer. American Journal of Surgical Research and Reviews, 2021; 4:26.

\section{eScîPub}

eSciPub LLC, Houston, TX USA. Website: https://escipub.com/ By using the site/services, you are agreeing to our Policies: https:// escipub.com/terms-privacy-policydisclaimer/ 


\section{Introduction:}

Esophageal cancer (EC) is one of the deadliest malignancies worldwide and is often diagnosed in advanced stages. It is the 8th most common cancer in the world and is the 6th most common cause of cancer related deaths, having a 5-year survival rate of less than $20 \%$ despite advances in treatment. It has a poor prognosis due to the late diagnosis and the lack of early presenting symptoms. In the United States, stage IV is the most common stage at the time of diagnosis, [1], with greater than $30 \%$ of patients having metastatic disease at presentation. Many countries over the world have endoscopic screening programs for the high risk populations, that give a promising improvement in their survival rates [1]. The screening of high risk populations for EC differs for the two epidemiologically and biologically distinct subtypes of esophageal cancer. Esophageal adenocarcinoma (EAC) is the most common subtype in the United States, UK, and Western Europe and has been linked to gastroesophageal reflux disease (GERD) and obesity. Esophageal squamous cell carcinoma (ESCC) is the more common subtype worldwide, accounting for over $80 \%$ of EC cases, ${ }^{[2]}$. ESCC is particularly prevalent in Asia, East Africa, and South America and is associated with tobacco, alcohol and consumption of nitrogenous foods. Rarely, other histological subtypes [sarcomas and small cell carcinomas] develop in the esophagus, comprising less than $1 \%-2 \%$ of all esophageal cancers, ${ }^{[3]}$. So, the burden of disease is predominantly comprised of ESCC and EAC, and as distinct entities with both regional and epidemiologic differences, the methods and approaches to screening differ. Over the last two decades, neoadjuvant chemo radiotherapy has been successfully introduced in the curative treatment of esophageal cancer leading to significant improvement of survival and quality of life ${ }^{[4-6]}$.

The prognosis of esophageal cancer is much affected by lymph node metastases (LNM) which are associated with poorer survival [7]. The advantage of neoadjuvant therapy is mainly in its potential to induce tumor regression and treat occult micro metastatic disease, improving the resectability rate and survival outcome ${ }^{[8-10]}$.

Patients and Methods:

\section{Case selection:}

Eighty-seven fit patients were recruited for this multi-institutional clinical prospective study in the period from the start of January 2014 to the end of December 2020, diagnosed as cancer esophagus in by endoscopic biopsy and underwent surgical treatment according to stage at National Cancer Institute ( $\mathrm{NCl}$ ), Cairo University, Tanta Cancer Center, Egypt, Surgical department, Menofiya faculty of medicine, Surgical department.

We excluded from this study; unfit patients, patients with distant metastasis and patients refused to be included in this study.

Written informed consent was taken from all patients, and the study was approved from the ethical commmitte of the participating centers.

All patients diagnosed preoperatively by endoscopic biopsy, staged by CTscans of neck,chest and abdomen and checked for fitness of surgery by means of routine lab. investigations, echocardiograph and pulmonary function tests when needed.

\section{Surgical interference:}

After full evaluation of all patients, decisions taken to proceed for surgery in the MDT board either after neo adjuvant or from the start, incisions and approaches differ according to the tumor location and extension.

Tumors of gasteroesophageal junction will be approached by laparotomy, while distal esophageal tumors will be treated by Ivor-Lewis approach, and proximal lesions will be resected by Mckeon approach or transhiatal resection.

\section{Pathological evaluation:}

The biopsy from all 87 cases was reviewed and assessed for the tumor size, depth of invasion, tumor grade and number of Lymph nodes infiltrated and dissected.

Tumor size was determined based on the measurement detected in the original surgical pathology report and confirmed by microscopic examination. For small tumors or tumors not grossly AJSRR: https://escipub.com/american-journal-of-surgical-research-and-reviews/ 
apparent, the size was determined by measuring the largest microscopic cross sectional size. For multifocal tumors, the size of the largest single focus was recorded. We used the median tumor size in our cohort $(3.0 \mathrm{~cm})$ as a cutoff for assessing risk of nodal metastasis. This cutoff has been previously reported as a risk factor for nodal metastasis ${ }^{[11]}$.

The depth of invasion into the layers of esophagus is determined and reviewed by another pathologist to confirm submucosal invasion (stage T1b) which is defined as extension of the tumor beyond the muscularis mucosae and into the submucosa; tumors not satisfying this criterion were classified as intra mucosal (pT1a). Further stratification of depth of invasion according to Liu et al ${ }^{[12]}$, intra mucosal adenocarcinomas were classified T1a-superficial if they were confined to the lamina propria, otherwise they were classified as T1a-deep. Submucosal adenocarcinomas were classified as T1b-superficial if they invaded less than half the thickness of the submucosa at the point of invasion and T1bdeep if they invaded more than half the submucosal thickness.

The tumor location, presence of lymph node metastases and the total lymph node count were determined based on the original surgical pathology report and confirmed on review. Tumors involving the esophagus or proximal stomach that invaded across the anatomic gastroesophageal junction were categorized as gastroesophageal junction adenocarcinomas. Tumors located in the lower esophagus that did not involve the anatomic gastroesophageal junction were categorized as lower esophageal, tumor located in the middle esophagus categorized as middle esophageal while tumors located in upper esophagus confirmed as upper esophageal tumors.

Data collection:

Demographic data (age,sex, presence of comorbidities), tumor pathological characteristics (site, type, size, grade, Tstage, L.N affection and number), type of surgical procedures, postoperative morbidity and mortality will be collected and recorded.

\section{Statistical Analysis:}

All data were statistically analyzed using Statistical Package of Social Science (SPSS). Quantitative data were expressed as a mean \pm standard deviation (SD) while qualitative data were expressed as frequency and percentages. Qualitative variables were compared using a chisquare test while Quantitative continuous data were compared using the Mann- Whitney test and on way Anova test. Scatter plot was measured for each scale was used to compare the accuracy of the studied models. A P value less than 0.05 was considered statistically significant. A univariant analysis with non-linear correlation (cubic spline functions) was used to evaluate the shape of the relationship between the continuous variables and outcome.

The primary endpoint of this study is the relation between the size of tumor and its impact on the depth of invasion into different layers of esophagus, and the number of Lymph nodes affected.

\section{Results:}

\section{Patient characteristics:}

.87 patients diagnosed with esophageal cancer enrolled in this study, 57 patients (65.5\%) were male and 30(34.5\%) were females and their age ranged from 15-72 years old with Median age of 53 years (47.5-59.5), Mean \pm SD. $51.70 \pm$ 11.37(Figure 1)

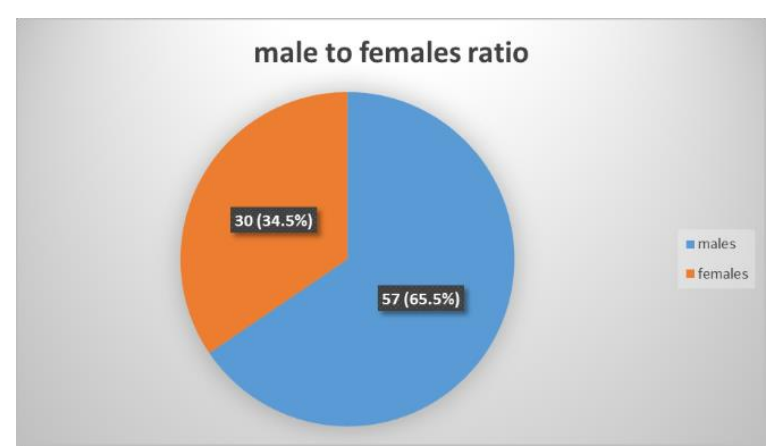


Dysphagia was the presenting symptom in $75 / 87$ $(86.8 \%)$ of the studied patients, while epigastric pain was the leading symptom in $22 / 87(13.2 \%)$ of them.

In this study, 57/87(65.5\%) of the patients found to have one or more chronic disease (hypertension. DM, ischemic heart disease, chronic asthma) while $30 / 87(34.5 \%)$ patients were fit without any comorbid or chronic disease. (Table 1)

In this study,neoadjuvant chemotherapy was schadueled in $20 / 87$ cases (23\%), ranged from $2-5$ courses of chemotherapy. (Table 1 )

Table (1): Distribution of the studied cases according to demographics and preoperative variables $(n=87)$

\begin{tabular}{|c|c|c|c|}
\hline \multirow{2}{*}{\multicolumn{4}{|c|}{ No. }} \\
\hline & & & \\
\hline Male & 57 & \multicolumn{2}{|l|}{65.5} \\
\hline Female & 30 & \multicolumn{2}{|l|}{34.5} \\
\hline \multicolumn{4}{|l|}{ Age (years) } \\
\hline Min. - Max. & \multicolumn{3}{|l|}{$15.0-72.0$} \\
\hline Mean \pm SD & \multicolumn{3}{|c|}{$51.70 \pm 11.37$} \\
\hline Median (IQR) & \multicolumn{3}{|c|}{$53.0(47.50-59.50)$} \\
\hline \multicolumn{4}{|l|}{ Complaint } \\
\hline Dysphagia & 75 & 86.2 & \\
\hline Epigastria pain & 12 & 13.8 & \\
\hline \multicolumn{4}{|l|}{ Comorbidity } \\
\hline No & 30 & & 34,5 \\
\hline Yes & 57 & 65,5 & \\
\hline \multicolumn{4}{|c|}{ Neo Adjuvant Treatment $(n=20)$} \\
\hline 2 cycles CTH & 1 & 5.0 & \\
\hline 3 cycles CTH & 11 & 55.0 & \\
\hline 4 cycles CTH & 3 & 15.0 & \\
\hline 5 cycles CTH & 5 & 25.0 & \\
\hline
\end{tabular}

\section{logical findings and locations:}

\section{picture:}

Malignant ulcer was found in $31 / 87$ patients (35.6\%) distributed as (23 in lower esophagus, 3 in middle esophagus, 3 in upper esophagus and 2 in gastro esophageal junction (GEJ)).

Fungating mass encountered in 18 cases (20.7\%) distributed as (16 in lower esophagus, 1 in middle esophagus and1 in upper esophagus).
Polypoid mass was found in $23 / 87$ cases (26.4\%) distributed as (18 in lower esophagus, 1 in upper esophagus, 2 in the middle esophagus and 2 in GEJ).

The remaining 15/87 cases presented with annular lesion stricture and distributed as (9 in lower esophagus, 2 in GEJ, 3 in middle esophagus and only one case in upper esophagus). Figure 2

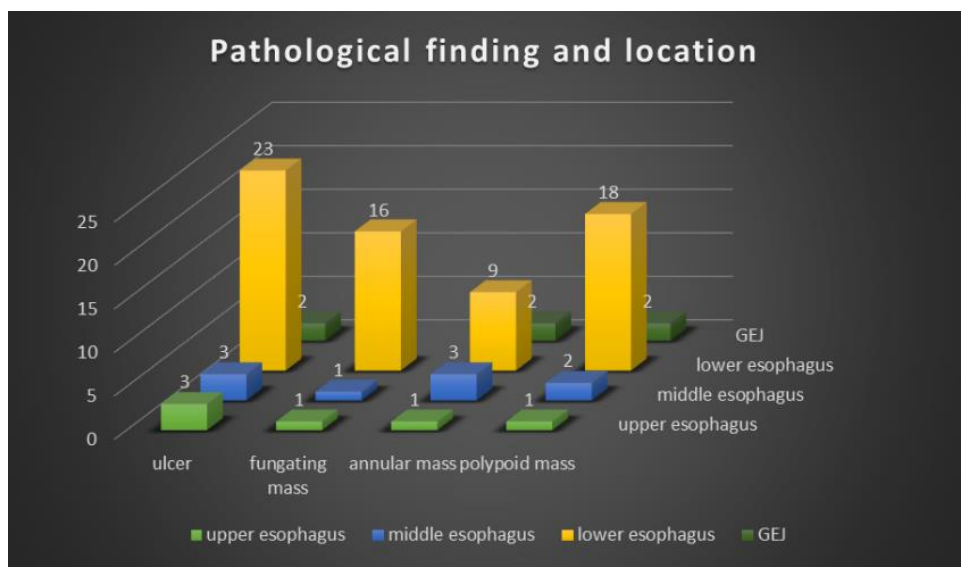




\section{Microscopic types:}

In pre-operative biopsy, Adenocarcinoma was diagnosed in 39/87 cases (44.8\%) distributed as (5 in GEJ and 34 diagnosed in lower esophagus) while squamous cell carcinoma (SCC) diagnosed in $48 / 87$ cases (55.2\%) distributed as (28 in lower part, 10 in middle part and 9 in upper esophagus respectively) and only one case out of 87 cases diagnosed as undifferentiated carcinoma of lower esophagus. (Table 2)

While post-operative pathological exam revealed adenocarcinoma in 40/87 (46\%) of cases, squamous cell carcinoma in 45/87(51.7\%) and adenosquamous carcinoma in $2 / 87(2.3 \%)$ of casesranged from Grade II in $64 / 87$ cases $(73.6 \%)$ and grade III in 21/87(26.4\%). (Table 2)

\section{Surgical details:}

There were different incisions and approaches for tumor resection in this study according to the tumor location and extension: 24/87(27.6\%) of cases approached through abdominal incision, $31 / 87$ (35.6\%) done by Ivor Lewis approach, trans hiatal approach was done in 13/87 cases (14.9\%) and Mckowen approach was adopted in $19 / 87$ cases $(21.8 \%)$.

In this study, 68/87(78.8\%) patients had hand sewen anastomosis while 19/87(21.2\%) had stapled anastomosis. (Table 2)

Intraoperative complications occurred in 29/87 $(33,4 \%)$ of the patients enrolled in this study (in the form of splenectomy, distal pancreatectomy, bleeding, pancreatic tear or injury of azygos vein or injury of bronchi with tracheostomy) and all these cases passed smoothly without any intra operative mortality.

Many post-operative complications recorded in 47 patients (54\%) as chest infections, Pneumonia, arrhythmia, medistinitis, pulmonary embolism, anastomotic leakage, reactionary bleeding, and wound infection and dehisence. (Table 3)

The 3 month post operative mortality was reporteded in 12/87 patients (13,8\%) \{Min. - Max. in days was $5.0-55.0$ days with Mean \pm SD $21.25 \pm 14.63$ and Median (IQR) 16.50(12.50 29.0). (Table 3)

(2): Distribution of the studied cases according to the pathology $(n=87)$

$\begin{array}{lll}\text { Gross picture } & & \\ \text { Ulcer } & \mathbf{3 1} & \mathbf{3 5 . 6} \\ \text { Lower esophagus } & 23 & 74.2 \\ \text { Middle esophagus } & 3 & 9.7 \\ \text { Upper esophagus } & 3 & 9.7 \\ \text { GEJ } & 2 & 6,4 \\ \text { Fun gating mass } & \mathbf{1 8} & \mathbf{2 0 . 7} \\ \text { Lower esophagus } & 16 & 88.9 \\ \text { Middle esophagus } & 1 & 5.6 \\ \text { Upper esophagus } & 1 & 5.6 \\ \text { Annular mass } & \mathbf{1 5} & \mathbf{1 7 . 2} \\ \text { Lower esophagus } & 9 & 60.0 \\ \text { Middle esophagus } & 3 & 20.0 \\ \text { Upper esophagus } & 1 & 6.7 \\ \text { GEJ } & 2 & 13.3 \\ \text { Polypoid mass } & \mathbf{2 3} & \mathbf{2 6 . 4} \\ \text { Lower esophagus } & 18 & 78.3 \\ \text { Middle esophagus } & 2 & 8.7 \\ \text { Upper esophagus } & 1 & 4.3 \\ \text { GEJ } & 2 & 8.6 \\ \text { Preoperative pathology (n }=\mathbf{8 7}) & & \\ \text { Adenocarcinoma } & \mathbf{3 9} & \mathbf{4 4 . 8} \\ \text { Adenocarcinoma of GEJ } & 5 & 12.8 \\ \text { ADC of lower esophagus } & 34 & 87.2 \\ \text { Squamous cell carcinoma } & \mathbf{4 8} & \mathbf{5 5 . 2}\end{array}$




$\begin{array}{lll}\text { SCC of lower esophagus } & 28 & 58.3 \\ \text { SCC of middle esophagus } & 10 & 20.8 \\ \text { SCC of upper esophagus } & 9 & 18.8 \\ \text { Undifferentiated carcinoma } & 1 & 2.1 \\ \text { Final Pathology ( } \mathbf{n}=\mathbf{8 7} \text { ) } & & \\ \text { Adenocarcinoma } & 40 & 46.0 \\ \text { Squamous cell carcinoma } & 45 & 51.7 \\ \text { Others (Adenosquamous) } & 2 & 2.3 \\ \text { Grade ( } \mathbf{n}=\mathbf{8 7} \text { ) } & & \\ \text { Grade II } & 64 & 73.6 \\ \text { Grade III } & 23 & 26.4\end{array}$

Table (3): Distribution of the studied cases according to the operative and postoperative variables

\begin{tabular}{|c|c|c|}
\hline \multicolumn{3}{|l|}{ procedure $(n=87)$} \\
\hline Abdominal & 24 & 27.6 \\
\hline Ivor Lewis & 31 & 35.6 \\
\hline Trans hiatal & 13 & 14.9 \\
\hline Mckowen & 19 & 21.8 \\
\hline \multicolumn{3}{|l|}{ Anastomosis $(n=87)$} \\
\hline Hand sewen & 68 & 78.2 \\
\hline Stapler & 19 & 21.8 \\
\hline \multicolumn{3}{|l|}{$\begin{array}{l}\text { Intra operative complications } \\
(\mathrm{n}=87)\end{array}$} \\
\hline No & 58 & 66,6 \\
\hline Yes & 29 & 33,4 \\
\hline \multicolumn{3}{|l|}{ Morbidity ( $n=87$ ) } \\
\hline No & 40 & 46.0 \\
\hline Yes & 47 & 54.0 \\
\hline \multicolumn{3}{|l|}{ Mortality (days) $(n=16)$} \\
\hline Min. - Max. & 5.0 & \\
\hline Mean \pm SD. & 21.2 & \\
\hline Median (IQR) & 16.5 & $-29.0)$ \\
\hline
\end{tabular}

Impact of tumor size on lymph nodes infilteration and depth of invasion:

The cutoff point in our study for the tumor size was $3 \mathrm{~cm}$.

As regards the tumor size; tumors $<3 \mathrm{~cm}$ was detected in $7 / 87$ patients (8\%), those $3-6 \mathrm{~cm}$ in size in $58 / 87(66.7 \%)$ while $22 / 87$ patients $(25.3 \%)$ had tumor size $>6 \mathrm{~cm}$ in diameter. (Table 4 ) The examination of the lymph node dissected in the resected specimens showed that there was 82 patients had $L N$ in the resected specimen: of them 40/82 had 1-10 LNs dissected, 26/82 had 11-20 LNs dissected and 16/82 had $>11$ nodes dissected with the maximum number of nodes dissected was 39 nodes.

After pathological examinations, we found that the number of nodes infiltrated by the tumor was
(0-5 nodes) in 20 patients (23\%) had while 6-10 affected nodes was detected in 7 (8\%) patients and 54 patients (62\%) had 11-20 nodes affected. (Table 4)

As regards the depth of invasion: most of the tumors resected invades the adventitia (63 pts., $72,3 \%$ ), and the relation between the size of the tumor and the depth of invasion is listed in Table 4.

We undergo Association between three groups according to tumor size (less than $3 \mathrm{~cm}, 3-6 \mathrm{~cm}$, more than $6 \mathrm{~cm}$ ) and its impact on depth of invasion and number of harvested lymph nodes. We found significant association between increase tumor size and increase depth of invasion to adventitia and increase of harvested lymph nodes more than 10 lymph nodes between between (< 
3) group and (3-6) group and between $(<3)$ group and $(>6)$ group. However, no correlation between increase of tumor size and increase depth of invasion nor more harvested lymph nodes between (3-6) group and (>6) group.

(4): Relation between tumor size and different parameters

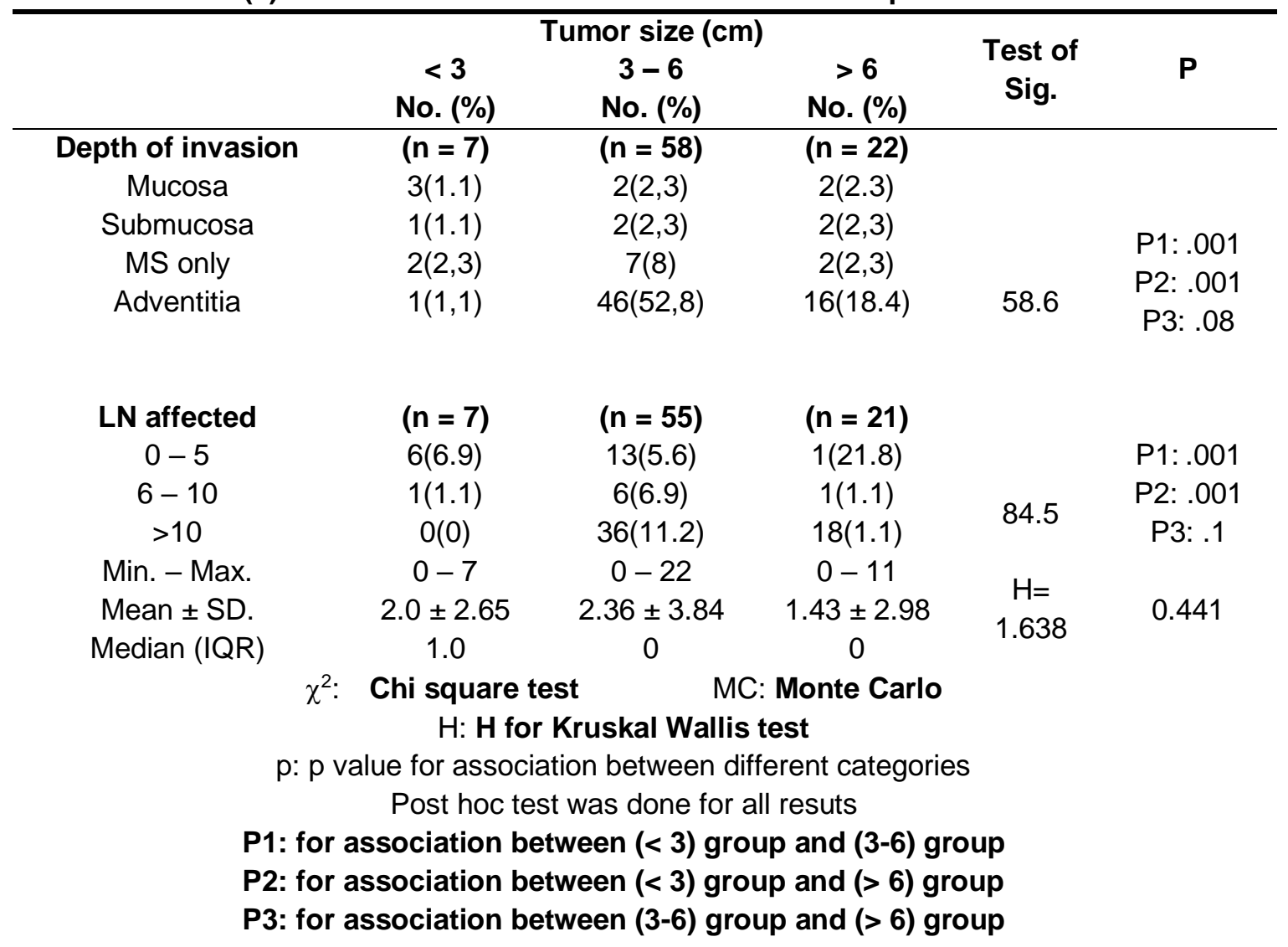

\section{Discussion:}

$\mathrm{EC}$ is an extremely aggressive malignancy with increasing incidence in recent years. Accurate disease staging system of patients is essential to determine appropriate treatment modalities and predict prognosis ${ }^{[13]}$. Tumor size is an easily measured variable before or during surgery, has been used as the T stage for many solid tumors, such as lung, breast, thyroid, uterine, and liver cancers ${ }^{[14-16]}$. Before 1987, esophageal tumor length $\leq 5 \mathrm{~cm}$ was categorized as $\mathrm{T} 1$ status and $>5 \mathrm{~cm}$ as T2 status by the 1983 version TNM staging system. However, tumor length was omitted and replaced by depth of the esophageal wall invasion in the 1987 version of the tumor staging system, and this modification has continued to the present ${ }^{[17-19]}$. Recently, the prognostic value of tumor size in EC has received increased importance again and pointed out by several previous studies as a non-negligible prognostic indicator that determines the survival of EC [2024]. However, no consensus has been reached about the role of tumor size in the disease because of the limitations in sample size, evaluation criteria, and variety of cut-off values.

In our study, we had 87 patients that all underwent surgery with 20 cases have neoadjuvant chemotherapy then surgery with determination of the size of the tumor from the start by radiological imaging pre-operative then the accurate measurement of size of the tumor by the pathologist at cutting and examining the specimen then the examination of the accurate depth of invasion and infiltration into the layers of esophageal tissues and also the detection of the number of lymph nodes affected and total number dissected with the characters of the tumor and grade for all specimens together with detection of the proximal and distal safety margin that may be risk factors for recurrence or 
mortality. We concentrate in this study then on the size of tumor and its relation and effect on the depth of invasion into layers of esophagus and the number of Lymph nodes affected as a prognostic factor and its effect and impact on long term survival.

Many studies done before worldwide to detect this relation, indicating the superiority of tumor size in EC, the definition of significant prognostic cut-off point varies among studies. Eloubeidi et al. ${ }^{[25]}$ analyzed the outcome of 10,441 EC patients from the database of the National Cancer Institute Surveillance, Epidemiology and End Results data to identify the prognostic factors of tumor size in patients with localized disease. They demonstrated that tumor size greater than $3 \mathrm{~cm}$ was associated with decreased overall survival (OS) when compared with shorter tumors. They also suggested that the $T$ status could be suffixed with either an "a" $(\leq 3 \mathrm{~cm})$ or "b" $(>3 \mathrm{~cm})$ to modify the current TNM staging. Meanwhile, Griffiths et al. ${ }^{[20]}$ and Yendamuri et al. ${ }^{[26]}$ retrospectively evaluated 309 and 209 EC patients after esophagectomy, and concluded that tumor size was an independent predictor of long-term survival for adenocarcinomas, except for ESCC when classified at a cut-off of $3.5 \mathrm{~cm}$. However, these two studies had difficulty in reaching a consistent conclusion based on such small numbers of patients with ESCC. Zeybek et al. ${ }^{[27]}$ categorized the maximum diameter of tumor into three subgroups ( $\leq 3 \mathrm{~cm}, 3-6 \mathrm{~cm}$ and $\geq 6 \mathrm{~cm}$ ), and they found that both the OS and diseasefree survival rates decreased with the increase in tumor size, especially in ESCC. In another study of patients with early EC, researchers found that esophageal tumor size $(>3 \mathrm{~cm})$ in combination with submucosal involvement may help identify the high-risk group of patients for adjuvant therapy and more extensive lymphadenectomy ${ }^{[28]}$. Tumor size is an important index that refers to the maximum diameter of the primary tumor, and it is easily measured before and during the operation ${ }^{[29]}$. Duan et al. reported that a tumor size larger than $2.5 \mathrm{~cm}$ was a risk factor for LNM, and the LNM rates of tumors smaller than $2.5 \mathrm{~cm}$ and larger than $2.5 \mathrm{~cm}$ were $9.8 \%$
(8/82) and 27.9\% (17/61), respectively [30]. $2 \mathrm{~cm}$ as the threshold was used, and the results showed that the LNM rates of tumors smaller than $2 \mathrm{~cm}$ and larger than $2 \mathrm{~cm}$ were $8.9 \%(8 / 90)$ and $24.8 \%$ (38/153), respectively.

In this study, the cut off point for size of tumor is $3 \mathrm{~cm}$ and all tumors measured and categorized as $<3 \mathrm{~cm}, 3-6 \mathrm{~cm}$ and $>6 \mathrm{~cm}$ and recorded together with the degree of invasion and number of lymph nodes and their effect on outcome and mortality with survival rate.

Subsequent analysis found that larger tumors were usually closely associated with a greater degree of malignancy and worse behavior. Furthermore, the patients with LSTs (Large size tumors) presented with worse prognosis than the patients with SSTs (Small size tumors), due to the aggressive features. In particular, tumor size was further demonstrated by multivariate analysis as an independent prognostic predictor along with invasion depth, lymph node metastasis, and histological type. This research suggested that tumor size could provide important information on malignant potential of tumors and outcomes. As we all known, the AJCC TNM staging system is important for assessing the prognosis of EC patients. Although tumor size was not included in the new staging system, our study verified that combination of tumor size and the TNM staging could enhance the accuracy of the AJCC TNM staging system alone in predicting the 5-year survival rate among ESCC patients who underwent curative surgery. As a result, tumor size may become another important indicator in the future AJCC TNM staging system.

Some possible mechanisms could explain the relationship between the tumor size and prognosis in EC patients. Firstly, the maximum diameter of tumor could provide important information useful for evaluating the potential effect of tumor doubling time on screening programs in terms of the degree of prognostic improvement. Secondly, the great association of a larger tumor size with a more intensive invasion depth, higher incidence of lymph node metastasis, and advanced TNM staging may reflect the value of tumor size as an indicator of aggressive biological ournal-of-surgical-research-and-reviews/ 
behavior of EC. Moreover, a large diameter of primary tumor was frequently characterized by histologically poorly differentiated type, which may account for its independent clinical value [31].

Notably, we found that invasion depth and lymph node involvement were powerful prognostic indicators. To eliminate any confounding effects on OS (overall survival), In some studies, analysis of patients according to lymph node status and invasion depth, showed that the SST groups presented a survival advantage over the LST groups for the lymph node-negative rather than the lymph node-positive patients, which is consistent with previous studies ${ }^{[32]}$. Furthermore, tumor size was further demonstrated as an independent prognostic factor, and the inclusion of tumor size could improve accuracy in patients assorted by $T$ stage for node-negative EC patients.

In our study, it was noted that the size of tumor is an important prognostic factor for the depth of invasion through the esophageal layers and the number of lymph nodes affected and so will affect the outcome and survival rate of patients, the tumor size more than $3 \mathrm{~cm}$ associated with increased depth of invasion in layers especially muscle layer and adventitia and associated also with increase number of lymph node infiltrated in specimens of resected tumor.

There are some limitations in this study: the relatively small number of patients, it was multi-institutional study, and the relatively short time of follow up which did not enable us to include the 5 -year survival rate in our data.

\section{Conclusion:}

The increased tumor size (cutoff point $3 \mathrm{~cm}$ ), is associated withthe more depth of invasion through the layers of esophagus and increased number of the infiltrated lymph nodes that is associated with poor prognosis and increase in mortality rate from the esophageal cancer.

Conflicts of interest: The authors declare no conflicts of interest.

Funding: This research did not receive any specific grant from funding agencies in the public, commercial, or not-for-profit sectors

\section{Abbreviations:}

\section{EC esophageal carcinoma}

ESCC esophageal squamous cell carcinoma

LSTs large size tumors

SSTs small size tumors

LNs Lymph nodes

OS overall survival

\section{GEJ gastro esophageal junction}

EAC esophageal adenocarcinoma

\section{References}

[1] Patel N, Benipal B. Incidence of esophageal cancer in the United States from 2001-2015:

United States Cancer Statistics Analysis of 50 states. Cureus. 2018; 10(12): e3709. PubMed Web of Science $₫ G o o g l e$ Scholar https://doi.org/10.1002/jso.25656

[2] Xie SH, Lagergren J. Risk factors for esophageal cancer. Best Pract Res Clin Gastroenterol. 2018; 36 - 37: 3 - 8. CrossRef PubMed Web of Science ${ }^{\circledR G}$ Google Scholar

[3] Zhang Y. Epidemiology of esophageal cancer. World J Gastroenterol. 2013; 19 (34): 5598- 5606.

[4] CrossRef PubMed Web of Science ${ }^{\circledR G}$ Google Scholar Lordick F, Mariette C, Haustermans K, et al. Esophageal cancer: ESMO clinical practice guidelines for diagnosis, treatment and followup. Ann Oncol 2016; 27: v50-v57. [PubMed] [Google Scholar]

[5] van Hagen P, Hulshof MC, van Lanschot JJ, et al. Preoperative chemo radiotherapy for esophageal or junctional cancer. $\mathrm{N}$ Engl $\mathrm{J}$ Med 2012; 366: 2074-2084. [PubMed] [Google Scholar]

[6] Noordman BJ, Verdam MGE, Lagarde SM, et al. Impact of neoadjuvant chemo radiotherapy on health-related quality of life in long-term survivors of esophageal or junctional cancer: Results from the randomized CROSS trial. Ann Oncol 2018; 29: 445-451. [PubMed] [Google Scholar]

[7] Lymph Node Metastases in Esophageal Carcinoma: An Endoscopist's View. Cho JW, Choi SC, Jang JY, Shin SK, Choi KD, Lee JH, Kim SG, Sung JK, Jeon SW, Choi IJ, Kim GH, Jee SR, Lee WS, Jung HY, Korean ESD Study Group. Clin Endosc. 2014 Nov; 47(6):523-9. [PubMed] [Ref list]

[8] Chemo radiotherapy in tumors of the esophagus and gastro-esophageal junction. Hulshof MC, van Laarhoven HW Best Pract Res Clin 
Gastroenterol. 2016 Aug; 30(4):551-63. [PubMed] [Ref list]

[9] Thies S, Langer R. Tumor regression grading of gastrointestinal carcinomas after neoadjuvant treatment. Front Oncol 2013; 3: 262. [PMC free article] [PubMed] [Google Scholar]

[10] Davarzani N, Hutchins GGA, West NP, et al. Prognostic value of pathological lymph node status and primary tumor regression grading following neoadjuvant chemotherapy - results from the MRC OE02 esophageal cancer trial. Histopathology 2018; 72: 1180-1188. [PMC free article] [PubMed] [Google Scholar

[11] Leers JM, DeMeester SR, Oezcelik A, et al. The prevalence of lymph node metastases in patients with T1 esophageal adenocarcinoma a retrospective review of esophagectomy specimens. Ann Surg. 2011; 253:271-8. [PubMed] [Google Scholar]

[12] Significance of the depth of tumor invasion and lymph node metastasis in superficially invasive (T1) esophageal adenocarcinoma. Liu L, Hofstetter WL, Rashid A, Swisher SG, Correa AM, Ajani JA, Hamilton SR, Wu TT Am J Surg Pathol. 2005 Aug; 29(8):1079-85. [PubMed] [Ref list]

[13] Strong VE, D'Amico TA, Kleinberg L, Ajani J. Impact of the 7th Edition AJCC staging classification on the NCCN clinical practice guidelines in oncology for gastric and esophageal cancers. J Natl Compr Canc Netw.2013;11:60-66. [PubMed] [Google Scholar

[14] Wittekind C. New TNM classification of lung tumors. Pathology. 2014 [PubMed] [GoogIScholar]

[15] Schwartz AM, Henson DE, Chen D, Rajamarthandan S. Histologic grade remains a prognostic factor for breast cancer regardless of the number of positive lymph nodes and tumor size: a study of 161708 cases of breast cancer from the SEER Program. Arch Pathol Lab Med. 2014;138:1048-1052. [PubMed] [Google Scholar]

[16] Duseja A. Staging of hepatocellular carcinoma. J Clin Exp Hepatol. 2014;4: S74-S79. [PMC free article] [PubMed] [Google Scholar]

[17] Edge SB, Compton CC. The American Joint Committee on Cancer: the 7th edition of the AJCC cancer staging manual and the future of TNM. Ann Surg Oncol. 2010;17:14711474. [PubMed] [Google Scholar

[18] lizuka T, Isono K, Kakegawa T, Watanabe H. Parameters linked to ten-year survival in Japan of resected esophageal carcinoma. Japanese Committee for Registration of Esophageal Carcinoma Cases. Chest. 1989; 96:10051011. [PubMed] [Google Scholar]
[19] Sobin LH, Hermanek P, Hutter RV. TNM classification of malignant tumors. A comparison between the new (1987) and the old editions. Cancer. 1988; 61:2310-2314. [PubMed] [Google Scholar]

[20] Griffiths EA, Brummell Z, Gorthi G, Pritchard SA, Welch IM. Tumor length as a prognostic factor in esophageal malignancy: univariate and multivariate survival analyses. J Surg Oncol. 2006; 93:258-267. [PubMed] [Google Scholar]

[21] Wu N, Pang LW, Chen ZM, Ma QY, Chen G. Tumor length is an independent prognostic factor of esophageal squamous cell carcinomas. Chin Med J (Engl) 2012;125:4445-4448. [PubMed] [Google Scholar]

[22] Wang BY, Liu CY, Lin CH, Hsu PK, Hsu WH, Wu $Y C$, Cheng CY. Endoscopic tumor length is an independent prognostic factor in esophageal squamous cell carcinoma. Ann Surg Oncol. 2012;19:2149-2158. [PubMed] [GoogleScholar]

[23] Feng JF, Huang Y, Zhao Q. Tumor length in elderly patients with esophageal squamous cell carcinoma: is it a prognostic factor? Ups J Med Sci. 2013;118:145-152. [PMC free article] [PubMed] [Google Scholar]

[24] Bollschweiler E, Baldus SE, Schroder W, Schneider PM, Holscher AH. Staging of esophageal carcinoma: length of tumor and number of involved regional lymph nodes. Are these independent prognostic factors? J Surg Oncol. 2006; 94:355-363. [PubMed] [Google Scholar

[25] Eloubeidi MA, Desmond R, Arguedas MR, Reed CE, Wilcox CM. Prognostic factors for the survival of patients with esophageal carcinoma in the U.S.: the importance of tumor length and lymph node status. Cancer. 2002; 95:14341443. [PubMed] [Google Scholar]

[26] Yendamuri S, Swisher SG, Correa AM, Hofstetter W, Ajani JA, Francis A, Maru D, Mehran RJ, Rice DC, Roth JA, Walsh GL, Vaporciyan AA. Esophageal tumor length is independently associated with long-term survival. Cancer. 2009; 115:508-516. [PubMed] [Google Scholar].

[27] Zeybek A, Erdogan A, Gulkesen KH, Ergin M, Sarper A, Dertsiz L, Demircan A. Significance of tumor length as prognostic factor for esophageal cancer. Int Surg. 2013; 98:234-240. [PMC free article] [PubMed] [Google Scholar]

[28] Bolton WD, Hofstetter WL, Francis AM, Correa AM, Ajani JA, Bhutani MS, Erasmus J, Komaki R, Maru DM, Mehran RJ, Rice DC, Roth JA, Vaporciyan AA, et al. Impact of tumor length on long-term survival of pT1 esophageal adenocarcinoma. J Thorac Cardiovascular Surg. 2009; 138:831-836. [PubMed] [Google Scholar 
[29] Zhang $\mathrm{H}$, Tang $\mathrm{P}$, Miao $\mathrm{X}$, et al. Does tumor size improve the accuracy of prognostic prediction in patients with esophageal squamous cell carcinoma after surgical resection? Oncotarget 2016; 7:66623-34. [PMC free article] [PubMed] [Google Scholar]

[30] Duan XF, Tang P, Shang XB, et al. The prevalence of lymph node metastasis for pathological T1 esophageal cancer: a retrospective study of 143 cases. Surg Oncol 2018; 27:1-6. 10.1016/j.suronc.2017.11.002 [PubMed] [CrossRef] [Google Scholar]
[31] Shen W, Shen Y, Tan L, et al. A nomogram for predicting lymph node metastasis in surgically resected T1 esophageal squamous cell carcinoma. J Thorac Dis 2018; 10:4178-85. 10.21037/jtd.2018.06.51 [PMC free article] [PubMed] [CrossRef] [Google Scholar

[32] Zhang $H$, Tang $P$, Miao $X$, et al. Does tumor size improve the accuracy of prognostic prediction in patients with esophageal squamous cell carcinoma after surgical resection? Oncotarget 2016; 7:66623-34. [PMC free article] [PubMed] [Google Scholar] 